\title{
Lipoteichoic acid from Lactobacillus rhamnosus GG as an oral photoprotective agent against UV-induced carcinogenesis
}

\author{
Federico S. Weill*, Eliana M. Cela, Mariela L. Paz, Alejandro Ferrari, Juliana Leoni and \\ Daniel H. González Maglio \\ Cátedra de Inmunología, Facultad de Farmacia y Bioquímica, Universidad de Buenos Aires, Junín 956, 4to Piso, \\ Ciudad Autónoma de Buenos Aires, C.P. 1113, Argentina
}

(Submitted 12 October 2011 - Final revision received 28 February 2012 - Accepted 29 February 2012 - First published online 6 July 2012)

\begin{abstract}
Probiotics are live micro-organisms that when administered in adequate amounts confer a health benefit on the host. Cell surface molecules of these micro-organisms are being studied in relation to their ability to interact with the host. The cell wall of lactobacilli possesses lipoteichoic acids (LTA) which are molecules with immunomodulatory properties. UV radiation (UVR) has been proposed as the main cause of skin cancer because of its mutagenic and immunosuppressive effects. Photoprotection with some nutrition interventions including probiotics has recently been shown. The aim of the present study was to investigate whether the oral administration of purified LTA from Lactobacillus rhamnosus GG can modulate the immune-suppressive effect of UVR and skin tumour development in female Crl:SKH-1-hrBR mice. For this purpose, two irradiation models were studied: (1) a chronic irradiation scheme consisting of daily irradiations during twenty consecutive days and (2) a long-term irradiation schedule, irradiating the animals three times per week, during 34 weeks for tumour development. The results showed that T-cells in the inguinal lymph node of LTA-treated mice produced higher levels of (1) interferon- $\gamma$ and (2) a number of total, helper and cytotoxic T-cells compared with non-treated mice. Moreover, a significant delay in tumour appearance was found in LTA-treated mice. An increased IgA ${ }^{+}$cell number was found in the small intestine together with a higher number of activated dendritic cells in the mesenteric lymph nodes. The latter results might be indicative of a direct effect of LTA in the gut, affecting the cutaneous immune system and restoring homeostasis through the gut-skin axis.
\end{abstract}

Key words: UV radiation: Probiotics: Skin cancer: Lipoteichoic acid

At the beginning of the nineteenth century, Elie Metchnikoff wrote his work The Prolongation of Life: Optimistic Studies ${ }^{(1)}$ where he stated that Bulgarians owed their longevity to the consumption of soured milk. Even if he did not use the term 'probiotic', which was first introduced in the $1960 \mathrm{~s}^{(2)}$, Metchnikoff had already identified yogurt as a functional food with important health benefits beyond nutrition.

Probiotics are defined as live microorganisms that when administered in adequate amounts confer a health benefit on the host ${ }^{\text {(3) }}$. These micro-organisms include different yeast and bacterial strains. The most studied bacterial genus within probiotics is Lactobacillus. Lactobacilli are lactic acid bacteria, associated with fermented foods mainly for their contribution to raw food preservation due to acidification and also because of their capacity to contribute to product characteristics such as flavour and texture ${ }^{(4)}$. Nutritional advantages of probiotics basically consist of preventive-curative effects against diseases including intestinal dysfunctions, gastrointestinal infections, inflammatory bowel disease and, possibly, colon cancer ${ }^{(5)}$.
Industrial interest on health claims related to probiotics has been a great impulse to molecular research on the host-probiotic interaction. Cell surface molecules and extracellular components of these micro-organisms are being studied in relation to their ability to interact with the host.

The cell wall of lactobacilli comprises peptidoglycan and teichoic acids. A great number of biological functions have been described for teichoic acid, e.g. surface protein binding, phage adsorption, cellular adhesion and interaction with the immune system. There are two types of teichoic acid described in lactobacilli: wall teichoic acids, which are bound to $N$-acetyl muramic acid of the peptidoglycan, and lipoteichoic acids (LTA), which are anchored to the cytoplasmic membrane through a glycolipid.

In terms of structure, LTA from lactobacilli are composed of poly-glycerol-phosphate (poly(Gro-P)), which are decorated by D-alanyl esters. D-Alanylation in lactobacilli is very important since it is involved in bacterial resistance to physico-chemical conditions of the gastrointestinal tract

Abbreviations: ConA, concanavalin A; DC, dendritic cells; GALT, gut-associated lymphoid tissue; ILN, inguinal lymph node; LTA, lipoteichoic acid; MLN, mesenteric lymph nodes; RPMI, Roswell Park Memorial Institute; UVR, UV radiation.

*Corresponding author: F. S. Weill, fax + 541149640024 , email fweill@ffyb.uba.ar 
and to defensins produced by the epithelial cells of the intestine $^{(6-9)}$.

Regarding its immunomodulatory effect, it is known that LTA can be recognised by Toll-like receptor type 2 . After ligand binding, Toll-like receptor type 2 sequentially recruits the adaptor molecules MyD88 (myeloid differentiation primary response gene 88), the IL-1 receptor-associated kinase and the TNF receptor-associated factor 6 . In turn, these adaptor molecules activate the IкB kinase complex and the mitogenactivated protein kinases Jun N-terminal kinase, p38 and extracellular signal-regulated kinases 1 and 2, leading to the activation of $\mathrm{NF}-\mathrm{\kappa B}$ and activator protein 1 , which results in the transcription of soluble mediators such as cytokines and chemokines $^{(10,11)}$.

LTA is one of the most important antigens in lactobacilli, as it has a key role in the crosstalk between the host and bacteria in the intestine. The release of soluble mediators after the LTA interaction with the epithelial and immune cells present in the intestine generates an inflammatory microenvironment and the recruitment of certain cell types, such as T- and B-cells. LTA activates B-cells in the lamina propria, causing the Ig class switch of these cells with the consequent production of secretory IgA, the main Ig involved in intestinal immunity ${ }^{(12)}$.

The effect of the oral administration of purified LTA has not been extensively studied. Literature data indicate its potential use in the prevention of group B streptococci infections in newborns. Cox et al. have evaluated LTA excretion and toxicity after oral administration to rabbits. In these studies, the amount of LTA administered was about $2-3 \mu \mathrm{g} / \mathrm{g}$ of animal weight, and they found LTA excretion in the urine and faeces until $4 \mathrm{~d}$ after the ingestion, with a peak of excretion at $24 \mathrm{~h}$. These authors did not find any pathological alteration in the liver, spleen or kidneys of animals receiving LTA ${ }^{(13)}$. Nevertheless, no study regarding LTA bioavailability has been performed to date.

UV radiation (UVR) is indispensable for life on earth; however, prolonged exposures can be dangerous for human health. UVR has been proposed as the main cause of skin cancer such as basal and squamous cell carcinoma and cutaneous malignant melanoma ${ }^{(14)}$. UVR causes direct damage to cellular DNA, tissue inflammation, immune response suppression and free radical formation with the consequent oxidation of proteins, lipids and $\mathrm{DNA}^{(15,16)}$. Additionally, it has been demonstrated that chronic irradiation causes epidermal hyperplasia ${ }^{(17)}$. Hyperplasia is a key event in skin carcinogenesis, specifically in non-melanoma tumours (mainly basal and squamous cell carcinomas) where keratinocytes are the affected cell type. Hyperplasia is a result of both increased epidermal proliferation and apoptosis suppression ${ }^{(18)}$. Nevertheless, the loss in proliferation control is not the only event related to UVR-induced tumorigenesis. UV-mediated immunosuppression has been recognised as a condition for skin tumour development ${ }^{(19)}$. Furthermore, another consequence of chronic UVR is increased inguinal lymph node (ILN) cellularity in the absence of antigenic stimuli ${ }^{(20)}$. Even if the mechanism underlying this event is unclear, it has been postulated as a prerequisite for further immunosuppression. One possibility is that the increase in the number of cells is the result of cell migration from other organs ${ }^{(21,22)}$
Over the last 30 years, the immunosuppressive effect of UVR has been studied and described. There is growing evidence about the key role of UV-induced regulatory T-cells during photocarcinogenesis, since they are capable of inhibiting antitumoral effector functions. After UVR exposure, a cytokine cascade is initiated biasing the immune response towards a $\mathrm{T}$ helper 2 or $\mathrm{T}$ regulatory phenotype, which finally leads to the emergence of $\mathrm{CD}^{+}{ }^{+}$-CTLA $4^{+}$regulatory T-cells. IL-10 and IL- 4 are the main cytokines involved in UV-induced immunosuppression. They are produced by T-cells, keratinocytes and other cell types in the skin after irradiation ${ }^{(23-25)}$.

The relationship between the gut and the cutaneous immune systems is not clear; however, there is evidence about the existence of a crosstalk between them. The beneficial effect of probiotic consumption on atopic eczema ${ }^{(26)}$, the development of specific IgA antibodies in gut-associated lymphoid tissue (GALT) after transcutaneous immunisation ${ }^{\text {(27) }}$ and the re-establishment of skin homeostasis due to probiotic consumption after UV irradiation are evidences for the existence of a gut-skin axis susceptible to modulation with therapeutic ends ${ }^{(28)}$.

Recently, photoprotection induced by specific nutrients has been demonstrated to be successful in preventing some of the harmful effects of $\mathrm{UVR}^{(29,30)}$. Over the last few years, probiotics have emerged as a new strategy in systemic photoprotection ${ }^{(30)}$. Gueniche et $_{\text {al }}{ }^{(27)}$ showed that a $10 \mathrm{~d}$ supplementation with a specific probiotic (Lactobacillus johnsonii) was able to revert some of the immunosuppressive effects of UVR in female SKH:hr1 hairless mice.

Based on this bulk of knowledge, the aim of the present study was to investigate whether the oral administration of purified LTA from Lactobacillus rhamnosus $G G$ (one of the most characterised probiotics) ${ }^{(31,32)}$ can modulate the immune-suppressive effect of UVR and prevent skin tumour development in female SKH:hr1 hairless mice. In this sense, anti-inflammatory cytokines such as IL-10 and IL- 4 were measured in cell-free culture supernatants of ILN and spleens from irradiated mice receiving LTA or PBS, or from a non-irradiated control group. Additionally, total T-cells $\left(\mathrm{CD}^{+}\right)$were determined in the epidermis and in the ILN, as well as helper $\left(\mathrm{CD} 3^{+} \mathrm{CD} 4^{+} \mathrm{CD} 8^{-}\right)$and cytotoxic T-cells $\left(\mathrm{CD}^{+} \mathrm{CD}^{-} \mathrm{CD}^{+}\right)$. Furthermore, the effect of LTA ingestion on GALT was analysed to study the mechanisms underlying its immunomodulatory effect. Total $\mathrm{IgA}^{+}$cells were determined in the lamina propria, and dendritic cells (DC) $\left(\mathrm{CD} 11 \mathrm{c}^{+}\right)$, activated $\mathrm{DC}\left(\mathrm{CD} 11 \mathrm{c}^{+} \mathrm{CD} 80^{+}\right)$and total activated antigen-presenting cells $\left(\mathrm{CD}^{+} 0^{+}\right)$were determined in the mesenteric lymph nodes (MLN).

For the present analysis, two irradiation models previously described by our group were used: a chronic irradiation scheme consisting of daily irradiations during twenty consecutive days, and a long-term irradiation schedule, irradiating the animals three times a week, during 34 weeks for tumour development ${ }^{(17,33)}$.

Our hypothesis was that the oral administration of LTA would modulate the GALT and that through the gut-skin immune axis, this would restore skin homeostasis affected by UVR, reducing UVR-induced tumorigenesis. 


\section{Materials and methods}

\section{Lipoteichoic acid purification}

LTA was isolated as described previously by Morath et al. ${ }^{(34)}$. Briefly, a previously established inoculum of $L$. rhamnosus $G G$ (American Type Culture Collection 53103) was cultured for $16 \mathrm{~h}$ in de Man-Rogosa-Sharpe (MRS) broth (Britannia). Bacteria were harvested by centrifugation and washed three times with PBS. The pellet was mixed with an equal volume of $n$-butanol, under stirring for $30 \mathrm{~min}$ at room temperature. After centrifugation at $13000 \mathbf{g}$ for $20 \mathrm{~min}$, the aqueous phase was lyophilised, resuspended with chromatography starting buffer (15\%n-propanol in $0.1 \mathrm{~m}$-ammonium acetate, $\mathrm{pH} 4.7$ ) and centrifuged at $45000 \mathrm{~g}$ for $15 \mathrm{~min}$. The supernatant was subjected to hydrophobic interaction chromatography in an octyl-sepharose matrix (GE Healthcare Life Sciences) eluting LTA with an increasing gradient of propanol. LTA-containing fractions were concentrated using vacuum centrifugation (Automatic Environmental Speedvac, Savant Instruments Inc.) in order to eliminate $n$-propanol. LTA preparation was tested for purity by Western blot, as described previously by Dogi et $a l^{(35)}$, and by spectrophotometry, as described previously by Kim et $a{ }^{(36)}$.

\section{Animal models and lipoteichoic acid administration}

Female Crl:SKH-1-hrBR hairless mice between 8 and 12 weeks of age (20-25 g), purchased from Charles River Laboratories, were housed in quarters with a $12 \mathrm{~h}$ light $-12 \mathrm{~h}$ dark cycle and maintained with water and food ad libitum.

The animals were irradiated on their back with UV light using an 8 W UVM-28 Mid-Range Wave (302 nm) lamp from Ultraviolet Products, which emits most of its energy within the UVB range (emission spectrum $280-370 \mathrm{~nm}$ ) with a peak at $302 \mathrm{~nm}$ and including a $20-30 \%$ amount of UVA. The lamp was calibrated with a UVX radiometer (Ultraviolet Products), and its power was determined as $1.2 \mathrm{~mW} / \mathrm{cm}^{2}$. Mice subjected to the chronic irradiation schedule (twelve animals) were exposed for $42 \mathrm{~s}$ to generate a dose of $50 \mathrm{~mJ} / \mathrm{cm}^{2}$ of UV corresponding to 0.25 minimal erythema dose. These animals were irradiated daily for twenty consecutive days. Mice in the long-term irradiation experiment (sixteen animals) were irradiated on their back with $50 \mathrm{~mJ} / \mathrm{cm}^{2}, 0.25$ minimal erythema dose every $2 \mathrm{~d}$ for a period of 34 weeks. These irradiation models have previously been established by our group ${ }^{(17,33)}$. In both irradiation schedules, half of the irradiated mice received $100 \mu$ l of LTA solution orally $(1 \mathrm{mg} / \mathrm{ml})$ in PBS before the irradiation, and the other half received $100 \mu \mathrm{l}$ PBS. The solutions were orally administered by means of a feeding needle (Thomas Scientific).

Simultaneously to each irradiation scheme, a group of mockirradiated sex- and age-matched mice were used as controls, and handled in the same fashion as the irradiated animals. A total of six control female mice were included in the chronic model and eight in the long-term irradiation scheme. At $24 \mathrm{~h}$ after the last UV irradiation, both chronically and long-term irradiated mice were killed using a $\mathrm{CO}_{2}$ gas chamber, and dorsal skin samples, ILN and spleens were removed. From chronically irradiated mice, four MLN and a small-intestinal section were obtained. The procedures involving animals were in compliance with the research animal use guidelines established by the Consejo Nacional de Investigaciones Científicas y Técnicas (Argentina) and were approved by the Review Board of Ethics of the Instituto de Estudios de la Inmunidad Humoral.

\section{Histology and epidermal thickness determination}

Specimens for histological examination were obtained from the skin of the irradiated area, fixed with $4 \%$ neutral formalin and embedded in white paraffin. Serial paraffin sections, $4 \mu \mathrm{m}$ thick, were prepared and stained with haematoxylin and eosin. At least three independent measurements were performed in two different slides per mouse. The observation and photography were performed using an Olympus BX-51 microscope (Olympus) with a $\mathrm{Q}$ color 3 Olympus digital camera. Epidermal thickness was measured with Image Pro 5.1.0.2 for Windows (Media Cybernetics)

\section{Epidermal cell isolation}

Skin samples of $1 \mathrm{~cm}^{2}$ were taken from each mouse. The samples were incubated with $25 \mathrm{mg} / \mathrm{ml}$ of dispase (Invitrogen) in Roswell Park Memorial Institute (RPMI) medium for $2 \mathrm{~h}$. After incubation, the epidermis was easily separated from the dermis. The epidermis was then manually dispersed with a tissue homogeniser (Thomas Scientific), passed through a $50 \mu \mathrm{m}$ filter and cells were counted and prepared for flow cytometric analysis.

\section{$\lg \mathrm{A}^{+}$cell count in the lamina propria}

The number of $\operatorname{IgA}^{+}$cells was determined on small-intestinal histological sections by a direct immunofluorescence assay. After deparaffinisation by immersion in xylene and rehydration in a graded ethanol series, paraffin sections $(4 \mu \mathrm{m})$ were incubated with a 1:100 dilution of fluorescein isothiocyanate (FITC)- $\alpha$-chain monospecific antibody (Bethyl) for $30 \mathrm{~min}$ and observed with an Olympus BX-51 fluorescence light microscope. The number of fluorescent cells was counted in forty fields at $1000 \times$.

\section{Measurement of apoptotic cells by the TUNEL method}

After deparaffinisation by immersion in xylene and rehydration in a graded ethanol series, the percentage of cells with DNA strand breaks in the assay epidermis was measured on paraffin sections $(4 \mu \mathrm{m})$ using the TUNEL (terminal deoxynucleotidyl transferase dUTP nick end labelling) method, which detects digoxigenin-labelled $3^{\prime}-\mathrm{OH}$ ends of genomic DNA. Briefly, cells with DNA strand breaks were detected in situ using the ApopTag Plus Peroxidase In Situ Apoptosis Detection Kit (CHEMICON International) according to the manufacturer's instructions. Counterstain was performed with eosin. Total and apoptotic cells in the epidermis (combined basal and suprabasal layers) were counted in ten representative $400 \times$ magnification fields using an Olympus BX-51 microscope (Olympus).

\section{In vitro proliferation}

ILN and spleens from UV-irradiated or control mice were manually dispersed with a tissue homogeniser (Thomas Scientific) 
and cells were counted and plated in ninety-six-well plates. Cells $\left(4 \times 10^{5}\right)$ were plated in replicates of three, together with $100 \mu$ l RPMI (Gibco) supplemented with $10 \%$ fetal calf serum, streptomycin $(100 \mu \mathrm{g} / \mathrm{ml})$ and penicillin (100 units $/ \mathrm{ml})$, as described elsewhere ${ }^{(37)}$. Cells were incubated with the non-specific T-cell mitogen concanavalin A (ConA) (Sigma) at $4,2,1,0.5$ and $0.25 \mu \mathrm{g} / \mathrm{ml}$. A basal proliferation control was also performed without the mitogen. After $72 \mathrm{~h}$ of incubation at $37^{\circ} \mathrm{C}$ with $5 \% \mathrm{CO}_{2}$, supernatants were collected for cytokine determination.

\section{Cytokine quantification in culture supernatants}

IL-4, IL-10 and interferon- $\gamma$ levels were measured by ELISA using the OPTEIA system (BD Biosciences) according to the manufacturer's instructions in cell-free culture supernatants of the cells treated with $4 \mu \mathrm{g} / \mathrm{ml}$ of ConA.

\section{Flow cytometric analysis}

The following anti-mouse antibodies were purchased from BD Biosciences: Alexa Fluor 647-anti-CD4, phycoerythrin (PE)-anti-CD8, PE-anti-CD11c, FITC-anti-CD80 and FITC-anti$\mathrm{CD} 3 \varepsilon$ with their corresponding isotype controls.

For staining of surface markers, lymph nodes and epidermal cells were incubated with antibodies diluted in staining buffer (PBS, 10\% fetal calf serum) for $30 \mathrm{~min}$ at $4{ }^{\circ} \mathrm{C}$, washed, and then fixed in $0.2 \mathrm{ml}$ of $2 \%$ formaldehyde (in PBS). Data were acquired on a PAS III cytometer (PARTEC) and analysed using Cyflogic software 1.2.1 (CyFlo Limited).

\section{Tumour number and size}

Mice were carefully examined once per week during the whole long-term irradiation model. The location and growth of each tumour exceeding $1 \mathrm{~mm}$ in diameter were determined and measured with a dermatoscope (Delta 20; Heine).

\section{Statistical analysis}

All values are presented as means with their standard errors. Statistical significance was evaluated using one-way or two-way ANOVA, according to the experimental design. When variables had a normal distribution and showed homoscedasticity, a parametric ANOVA and Student-Newman-Keuls post boc test were used. When samples did not have a normal distribution and did not show heteroscedasticity, a non-parametric ANOVA and Dunn post hoc test were used. Kaplan-Meier survival curve analysis was performed using log-rank and Wilcoxon-Gehan analysis. Graphical and statistical analyses were performed with GraphPad Prism 5.0 (GraphPad Software) and GraphPad Instat 2.0 (GraphPad Software), respectively. Values were considered significantly different at $P<0.05$.

\section{Results}

\section{Histology and epidermal thickness determination}

The effects of oral LTA administration on histological alterations produced in the epidermis by UV exposure were studied in skin sections, both in the chronic irradiation model and in the longterm irradiation scheme. An increase in epidermal thickness was observed in chronically irradiated mice receiving LTA and PBS (36.37 (sE 7.20) $\mu \mathrm{m}$ and 44.69 (SE 8.81) $\mu \mathrm{m}$, respectively) compared with the control group $(26.42$ (SE 2.82) $\mu \mathrm{m})(P<0.05)$. No differences were found between the LTA and PBS treatments. Similar results were observed in the long-term irradiated mice. Those animals receiving LTA and PBS had an epidermal thickness of 68.05 (SE 5.56) $\mu \mathrm{m}$ and 65.92 (SE 6.38) $\mu \mathrm{m}$, respectively, whereas the value for the control group was significantly lower (18.20 (se 1.42) $\mu \mathrm{m})(P<0.05$; Table 1$)$.

\section{Apoptotic cell percentage in the epidermis}

In both irradiation models, UV exposure induced significant levels of apoptosis. Chronically irradiated mice receiving LTA had 22.43 (sE 1.38 ) \% of apoptotic cells; this value was not significantly different from the percentages obtained in mice treated with PBS which had 22.35 (SE 0.89)\% (Fig. 1(a)). The percentage of apoptotic cells in the control group was 12.55 (SE 0.81$) \%$, which was significantly lower $(P<0.05)$ than that obtained in irradiated mice. Long-term irradiated mice receiving LTA had 31.26 (SE 2.08) \% of apoptotic cells, this percentage was not statistically different from that obtained in mice receiving PBS (28.76 (SE 1.77)\%). Percentages obtained in the control group were significantly lower than those obtained in irradiated mice (17.62 (SE 1.66) \%, $P<0 \cdot 05$; Fig. 1(b)).

\section{Epidermal T-cell number}

UVR caused a decrease in epidermal T-cell percentage in both irradiation schemes. Chronically irradiated mice receiving

Table 1. Mean epidermal thickness, epidermal $\mathrm{CD}^{+}$cells and inguinal lymph node (ILN) cell number in chronically and long-term irradiated mice (Mean values with their standard errors)

\begin{tabular}{|c|c|c|c|c|c|c|c|c|c|c|c|c|}
\hline & \multicolumn{6}{|c|}{ Chronic irradiation } & \multicolumn{6}{|c|}{ Long-term irradiation } \\
\hline & \multicolumn{2}{|c|}{ Control } & \multicolumn{2}{|c|}{ LTA } & \multicolumn{2}{|c|}{ PBS } & \multicolumn{2}{|c|}{ Control } & \multicolumn{2}{|c|}{ LTA } & \multicolumn{2}{|c|}{ PBS } \\
\hline & Mean & SE & Mean & SE & Mean & SE & Mean & SE & Mean & SE & Mean & SE \\
\hline Epidermal thickness $(\mu \mathrm{m})$ & $26 \cdot 42^{\mathrm{b}}$ & $2 \cdot 82$ & $36 \cdot 37^{a}$ & $7 \cdot 20$ & $44 \cdot 69^{a}$ & 8.81 & $18 \cdot 20^{\mathrm{b}}$ & 1.42 & $68.05^{\mathrm{a}}$ & 5.56 & $65 \cdot 92^{\mathrm{a}}$ & 6.38 \\
\hline Epidermal $\mathrm{CD}^{+}$cells $(\%)$ & $7 \cdot 14^{\mathrm{b}}$ & 0.49 & $0.91^{\mathrm{a}}$ & 0.18 & $0.61^{a}$ & 0.05 & $5 \cdot 99^{\mathrm{b}}$ & 0.45 & $0.32^{\mathrm{a}}$ & 0.08 & $0.87^{a}$ & 0.16 \\
\hline ILN cell number $\left(\times 10^{7}\right)$ & $1 \cdot 14^{\mathrm{a}}$ & 0.14 & $2 \cdot 10^{\mathrm{b}}$ & 0.16 & $1.50^{\mathrm{a}}$ & 0.14 & $0.89^{a}$ & 0.15 & $3 \cdot 35^{\mathrm{b}}$ & 0.31 & $4.69^{c}$ & 0.27 \\
\hline
\end{tabular}

LTA, lipoteichoic acid

a,b,c Mean values within a row with unlike letters were significantly different $(P<0.05)$. 

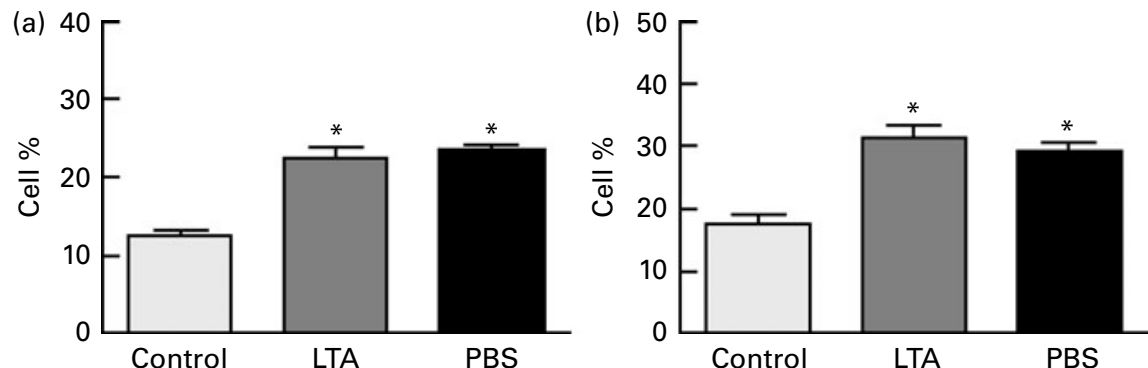

Fig. 1. Percentage of terminal deoxynucleotidyl transferase dUTP nick end labelling (TUNEL)-positive cells in the epidermis after (a) chronic and (b) long-term irradiation from control mice and from mice receiving lipoteichoic acid (LTA) or PBS. Values are means ( $n 6$ for chronically irradiated and $n 8$ for long-term irradiated mice), with standard errors represented by vertical bars. ${ }^{*}$ Mean value was significantly different from that of the control mice $(P<0.05)$.

LTA had 0.91 (SE $0 \cdot 18$ ) \% of epidermal T-cells; this value was not different from that obtained in mice treated with PBS which had 0.61 (SE 0.05 ) $\%$ of T-cells. The percentage obtained in the control group was significantly higher than that observed in both irradiated groups (7.14 (SE 0.49)\%, $P<0.05)$. Long-term irradiated mice receiving LTA had 0.32 (sE 0.08$) \%$ of epidermal T-cells, whereas the animals administered with PBS had 0.87 (SE 0.16)\%; these percentages were not statistically different from each other. However, the latter T-cell percentages were found to be lower than that obtained in the control group $(P<0.05)$ which was $5.99($ SE 0.45$) \%$ (Table 1).

\section{Cytokine production by inguinal lymph node and spleen T-cells}

When analysing cytokine production in ConA-stimulated ILN cells, chronically irradiated mice receiving LTA and PBS showed an increase in IL- 4 and IL-10 production compared with the control animals $(P<0.05)$. IL-4 production in LTA-treated mice was $240 \cdot 70$ ( $\mathrm{se} 37 \cdot 82) \mathrm{pg} / \mathrm{ml}$, a value that was not statistically different from the production in PBS-treated mice which was 252.20 ( $\mathrm{sE} \mathrm{36.47)} \mathrm{pg/ml.} \mathrm{The} \mathrm{production} \mathrm{of}$ IL-4 in the control group was 83.92 (sE 17.67) pg/ml (Fig. 2(a)) In the case of IL-10, the production in mice administered with LTA was 838.50 (SE 109.40) $\mathrm{pg} / \mathrm{ml}$, a value that was not different
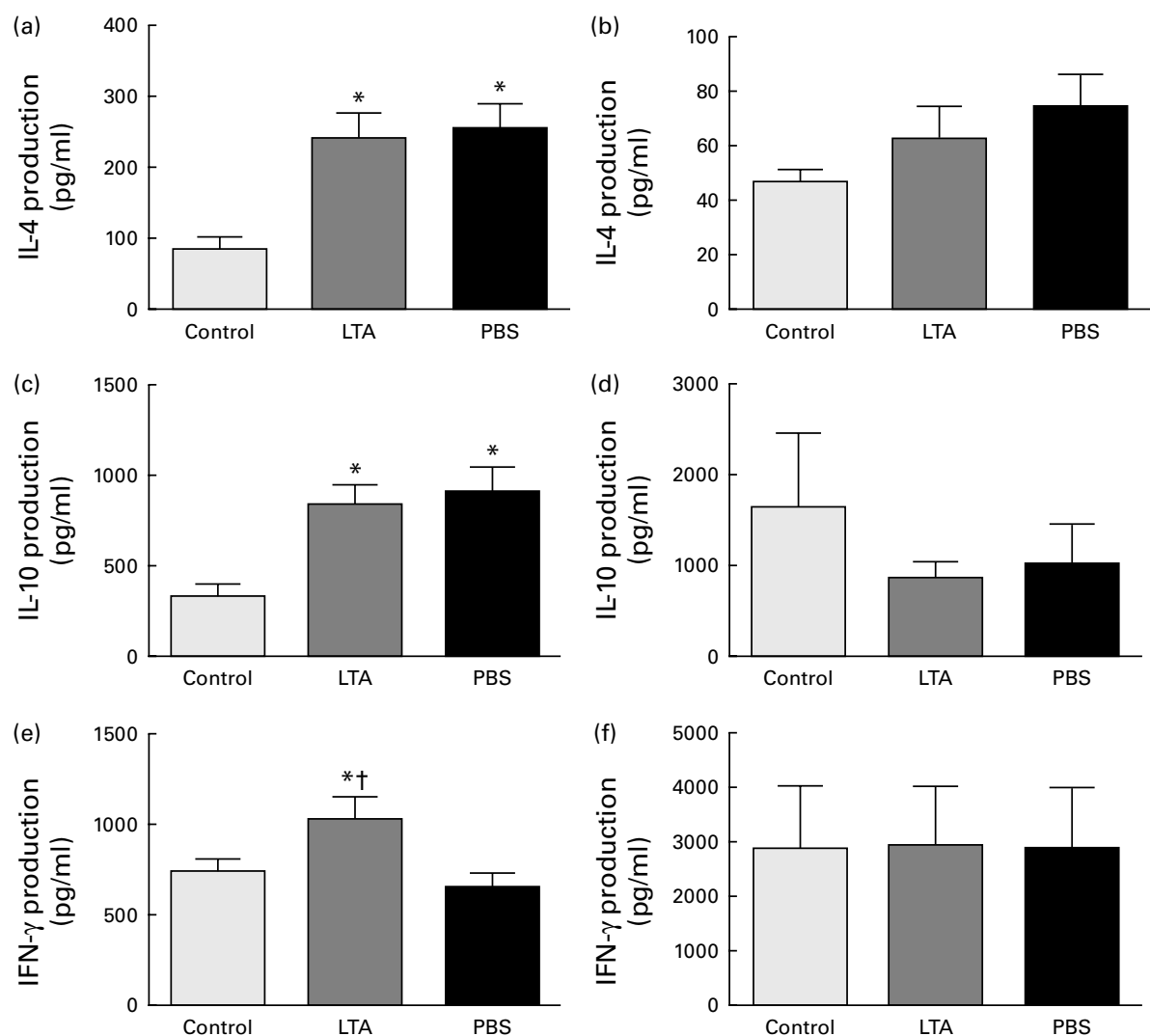

Fig. 2. Cytokine production in inguinal lymph node cells from (a, c, e) chronically and (b, d, f) long-term irradiated mice receiving lipoteichoic acid (LTA) or PBS and from the non-irradiated control group. Values are means ( $n 6$ for chronically irradiated and $n 8$ for long-term irradiated mice), with standard errors represented by vertical bars. * Mean value was significantly different from that of the control mice $(P<0.05)$. ${ }^{\dagger}$ Mean value was significantly different from that of the PBStreated mice $(P<0.05)$. IFN- $\gamma$, interferon- $\gamma$. 
from that in PBS-administered animals which was 921.00 (SE 121.50$) \mathrm{pg} / \mathrm{ml}$. The production of IL-10 in the control group was 340.70 (SE 76.78) pg/ml (Fig. 2(c)). Interferon- $\gamma$ production was significantly increased in mice treated with LTA (1033.10 (sE 126.15) pg/ml) compared with PBS-treated (658.20 $(\mathrm{SE} 73 \cdot 86) \mathrm{pg} / \mathrm{ml})$ and non-irradiated mice $(733.80(\mathrm{SE} 70 \cdot 43) \mathrm{pg} / \mathrm{ml})$ $(P<0.05$; Fig. 2(e)). In long-term irradiated mice, no statistical differences were detected for any cytokine (Fig. 2(b), (d) and (f)). No statistical differences were found in cytokine production by ConA-stimulated spleen cells from none of the groups in both irradiation models (data not shown).

\section{Total cell count in the inguinal lymph node and spleen}

In the chronically irradiated animals, the number of ILN cells in LTA-treated mice was $2 \cdot 10(\operatorname{se} 0 \cdot 16) \times 10^{7}$, a value that was significantly higher than the number obtained in PBS-treated (1.50 $\left.(\operatorname{SE} 0 \cdot 14) \times 10^{7}\right)$ and control mice $\left(1.14(\operatorname{se~} 0.14) \times 10^{7}\right)$. The long-term irradiated animals showed an increase in ILN cell number compared with control mice $\left(0.89(\right.$ SE 0.15$) \times 10^{7}$, $P<0 \cdot 05)$. The number of ILN cells in the PBS-treated group $\left(4.69(\right.$ SE 0.27$\left.) \times 10^{7}\right)$ was also significantly higher $(P<0.05)$ than those in LTA-treated mice $\left(3.35(\operatorname{se~} 0.31) \times 10^{7}\right)$ (Table 1$)$. No differences were found in spleen cell number in either of the irradiation schemes (data not shown).

\section{Phenotypic distribution of inguinal lymph node T-cell populations}

In order to assess the effect of skin irradiation on ILN, helper $\left(\mathrm{CD}^{+} \mathrm{CD}^{+} \mathrm{CD}^{-}\right)$, cytotoxic $\left(\mathrm{CD}^{+} \mathrm{CD}^{-} \mathrm{CD}^{+}\right)$and total T-cell $\left(\mathrm{CD}^{+}\right)$number were determined by flow cytometry. After chronic irradiation, helper T-cell number was significantly higher $(P<0.05)$ in LTA-treated mice $\left(19.98(\right.$ se 0.83$) \times 10^{6}$ than in the PBS-treated $\left(13.01(\operatorname{se~} 2.50) \times 10^{6}\right)$ and control $\left(11.69(\right.$ se 1.35$\left.) \times 10^{6}\right)$ groups. As for cytotoxic T-cells, the results were similar, with a significant increase detected in the LTA group $\left(13.23(\mathrm{SE} 0.73) \times 10^{6}\right)$ compared with PBS-treated $\left(6.93(\mathrm{SE} 1.13) \times 10^{6}\right)$ and control $\left(7.19(\mathrm{SE} \quad 0.73) \times 10^{6}\right)$ mice $(P<0.05)$. Total T-cell number in LTA-treated mice was 35.00 (SE 1.61$) \times 10^{6}$, this number was significantly higher $(P<0.05)$ than the number obtained in PBS-treated $(22.12$ $\left.(\mathrm{SE} 3.99) \times 10^{6}\right)$ and control $\left(22.83(\mathrm{SE} 2.51) \times 10^{6}\right)$ mice (Fig. 3(c), (e) and (g)). In the long-term irradiation model, total T-cell number was significantly increased in PBS-treated mice $\left(37.33(\mathrm{SE} 1.98) \times 10^{6}\right)$ compared with LTA-treated $(26.50$ $\left.(\mathrm{SE} 2.68) \times 10^{6}\right)$ and control $\left(26.13\left(\mathrm{SE} \mathrm{3.16)} \times 10^{6}\right)\right.$ mice $(P<0 \cdot 05)$. Helper T-cell number was also significantly increased $(P<0.05)$ in PBS-treated mice $\left(16.13(\right.$ SE 0.98$\left.) \times 10^{6}\right)$ compared with LTA-treated $\left(10.64(\mathrm{SE} 1.12) \times 10^{6}\right)$ and control mice $(8.02$ $\left.(\mathrm{SE} 1 \cdot 19) \times 10^{6}\right)$. The number of cytotoxic T-cells was also significantly higher $(P<0.05)$ in PBS-treated mice $(16.15$ $\left.(\operatorname{SE~} 1 \cdot 12) \times 10^{6}\right)$ than in LTA-treated $\left(8.26(\operatorname{SE~} 0.88) \times 10^{6}\right)$ and control $\left(8.54(\right.$ SE 1.26$\left.) \times 10^{6}\right)$ mice (Fig. 3(d), (f) and (h)).

\section{$\lg A^{+}$cell count in the small-intestinal lamina propria}

The number of IgA-producing B-cells in the lamina propria (Fig. 4(b)) of the chronically irradiated animals treated with
LTA was $804 \cdot 00$ (SE 18.26). This value was significantly higher $(P<0.05)$ than the number found in PBS-treated $(427 \cdot 70$ (SE 62.76)) and control mice (528.80 (SE 67.12)) (Fig. 4(a)).

\section{Antigen-presenting cell analysis in the mesenteric lymph nodes}

Total DC $\left(\mathrm{CD} 11 \mathrm{c}^{+}\right)$, activated DC $\left(\mathrm{CD} 11 \mathrm{c}^{+} \mathrm{CD} 80^{+}\right)$and total activated antigen-presenting cell $\left(\mathrm{CD}^{+}\right)$numbers in the MLN were determined by flow cytometry in the chronic irradiation model. A significant increase in activated DC (Fig. 5(d)) was detected in LTA-treated mice (2410.00 (SE 427.20)) compared with PBS-treated (1451.00 (SE 192.80)) and control $(994.00(\operatorname{se~} 159 \cdot 40))$ mice $(P<0 \cdot 05)$. Total activated antigen-presenting cell number (Fig. 5(c)) was also significantly increased $(P<0.05)$ in LTA-treated mice $(94721.00$ (SE 14788.00)) compared with control (43634.00 (sE 9555.00)) and PBS-treated (12 257.00 (SE 734.00)) mice. No significant differences were found for the total DC number (Fig. 5(b)) between the groups.

\section{Tumour appearance kinetics}

Tumour appearance was simultaneous in the LTA- and PBStreated animals and began around week 20. Nevertheless, LTA-treated mice showed a significant slower progression in tumour number, statistically compared with PBS-treated mice (Fig. 6(a)). When the appearance of the fourth tumour was taken as a death event for a death curve analysis, the difference between LTA- and PBS-treated mice was significantly different. Furthermore, the group of LTA-treated mice showed a 4-week delay in the detection of the first animal with four tumours (Fig. 6(b)). No tumour was detected in the control group throughout the study.

Average tumour size was not different between the irradiated groups along the study (Fig. 6(c)).

\section{Discussion}

The intake of some micro-organisms causes alterations in the complex interactions between the immune system and intestinal microbiota, and this does not only affect the GALT and the other mucosal-associated lymphoid tissues, but it also affects, in some way or another, the whole organism.

In the present study, LTA from $L$. rhamnosus $G G$ was employed. L. rhamnosus $G G$ is one of the probiotic bacteria with the most impressive scientific support as reviewed by Goldin \& Gorbach ${ }^{(32)}$. This antigen represents about $50 \%$ of the total weight of the Lactobacillus cell wall ${ }^{(4)}$ and is one of the strongest immunomodulators in this group of microorganisms.

A model of chronic irradiation, which had already been set up in our laboratory ${ }^{(33)}$, was used to study, first, the effect of LTA ingestion in an irradiation scheme applied for a shorter time than that required to induce tumorigenesis.

The results demonstrated that LTA ingestion did not improve UVR-induced epidermal cell alterations, since it did not modify the increase in epidermal thickness, the number of 


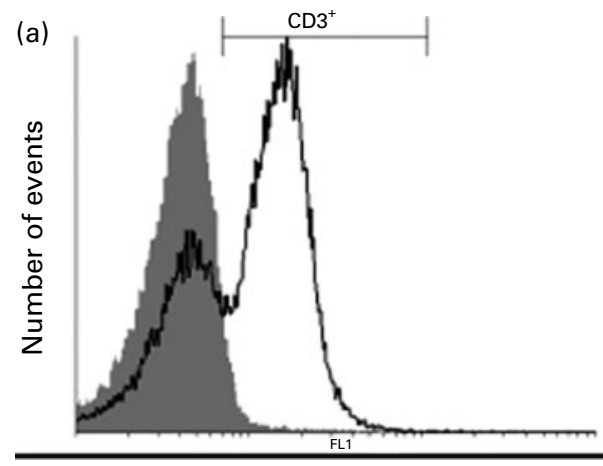

(c)

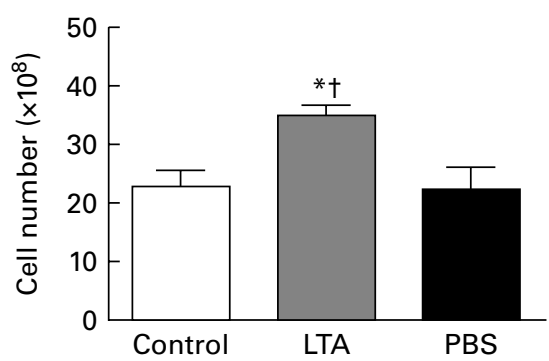

(e)

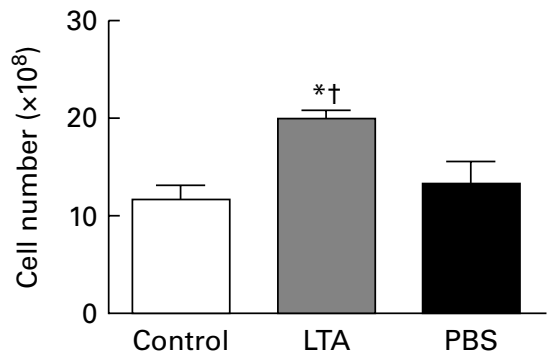

(g)

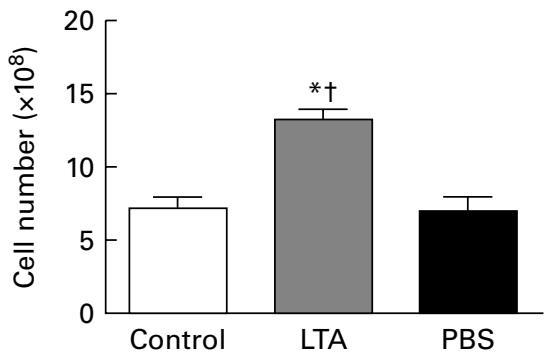

(b)

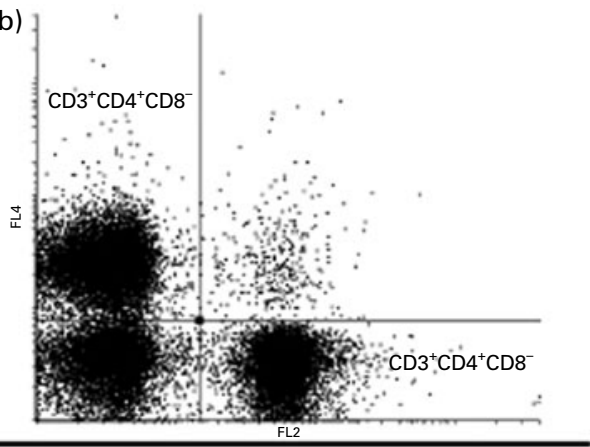

(d)

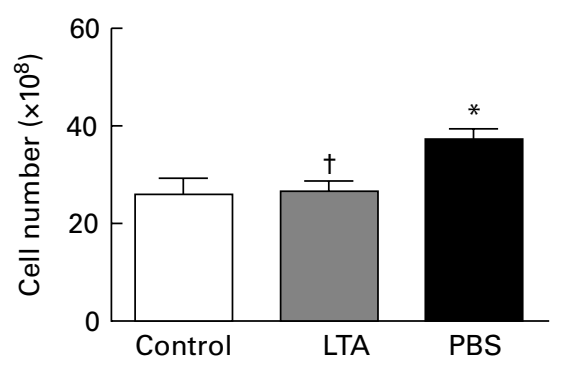

(f)

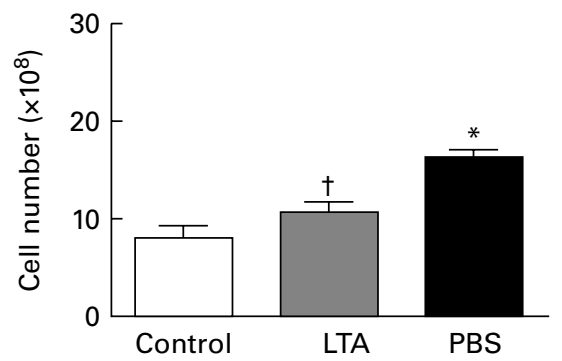

(h)

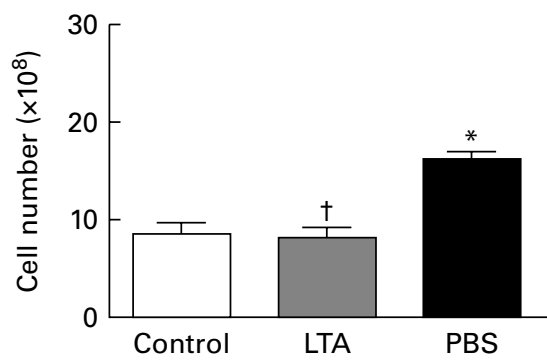

Fig. 3. T-cell populations in (c, e, g) chronically and ( $d, f, h)$ long-term irradiated mice receiving lipoteichoic acid (LTA) or PBS and in the non-irradiated control group. Values are means of total cell number ( $n 6$ for chronically irradiated and $n 8$ for long-term irradiated mice), with standard errors represented by vertical bars. (a) Histogram showing the $\mathrm{CD}^{+}$population and (b) dot plot showing the $\mathrm{CD}^{+} \mathrm{CD} 4^{+} \mathrm{CD} 8^{-}$and $\mathrm{CD} 3^{+} \mathrm{CD} 4^{-} \mathrm{CD} 8^{+}$cells. $\mathrm{FL} 1$, fluorescein isothiocyanate (FITC) anti-CD3 detection; FL2, phycoerythrin (PE) anti-CD8 detection; FL4, Alexa Fluor 647 anti-CD4 detection. * Mean value was significantly different from that of the control mice $(P<0.05) .{ }^{\dagger}$ Mean value was significantly different from that of the PBS-treated mice $(P<0.05)$.

apoptotic cells and the decrease in intraepithelial T-cells. LTA consumption did not affect IL-10 and IL-4 production by ConA-stimulated ILN T-cells, which were increased after UVR skin exposure. Nevertheless, T-cells from the LTA-treated animals showed a significant increase in interferon- $\gamma$ levels, compared with the controls and mice treated with PBS. This result would indicate a partial restoration of homeostasis in the draining lymph nodes, since interferon- $\boldsymbol{\gamma}$ is a cytokine classically associated with inflammatory processes which would be opposing the effect of IL-10 and IL- $4^{(38)}$.

Flow cytometric analysis of ILN T-cell populations showed an increase in total, helper and cytotoxic T-cells in mice treated with LTA. This phenomenon could be associated with the increased number of activated DC, which is also observed in the MLN of these mice. Indeed, activated DC activate T-cells that express $\alpha 4 \beta 7$ integrin, which binds mucosal addressin 
(a)

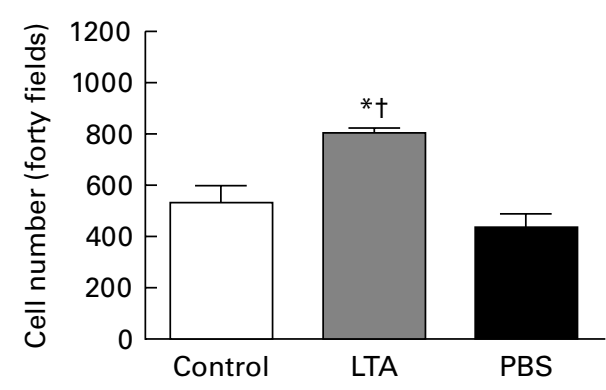

(b)

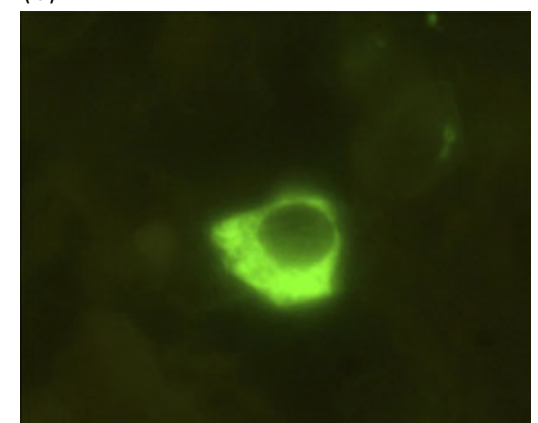

Fig. 4. (a) IgA-positive cells in the lamina propria of chronically irradiated mice. (b) Small-intestinal samples were stained with FITC-anti-IgA antibodies and positive cells were counted in forty fields per animal. Values are means, with standard errors represented by vertical bars. ${ }^{*}$ Mean value was significantly different from that of the control mice $(P<0.05)$. $†$ Mean value was significantly different from that of the PBS-treated mice $(P<0.05)$. (A colour version of this figure can be found online at http://www.journals.cambridge.org/bjn).

cell adhesion molecule-1, a molecule constitutively expressed in the mucosal-associated lymphoid tissues ${ }^{(39)}$. Recently, Ohmatsu et al. ${ }^{(40)}$ have shown that this integrin mediates lymphocyte migration to the skin under inflammatory conditions. Therefore, it is possible that after UVR-induced tissue damage, T-cells already activated in the MLN may migrate to the cutaneous immune system. This phenomenon, in association with the higher number of activated DC in the MLN of LTAtreated mice, might be responsible for the increased number of T-cells in the skin-draining lymph nodes of these animals.

In order to assess the effect of LTA on the intestinal immune cells, lamina propria $\operatorname{IgA}^{+}$cells were counted. After LTA consumption, a significant increase in the number of these cells was observed. B-cell activation by LTA can occur by its binding to Toll-like receptor type 2 or by crosslinking B-cell receptors.

(a)

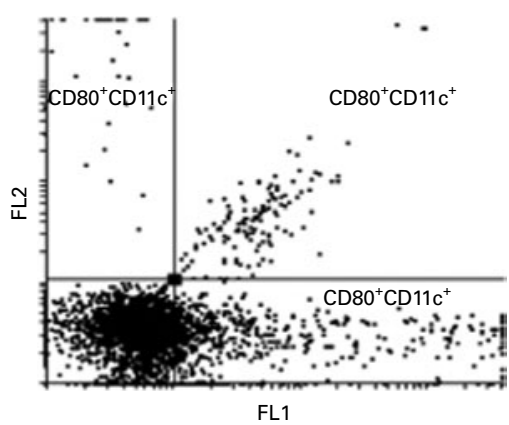

(c)

Total CD80+

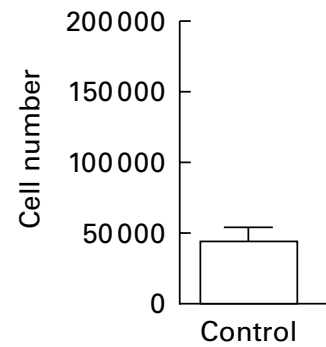

LTA can reach lamina propia B-cells directly by diffusion through the intestinal epithelial cells or by internalisation (non-degradative endocytosis) into DC which afterwards present LTA to B-cells in the lamina propria. Once the lamina propria B-cells are activated, they produce IgA with multiple specificities and low affinity. These Ig mediate commensal bacteria exclusion and protection from some pathogens such as rotaviruses and Salmonella typhimurium ${ }^{(12)}$. These results indicate that the oral administration of LTA had a direct effect on the GALT, in particular on B-cells.

Considering the photoprotective effects of LTA administration on the chronic irradiation model, we decided to evaluate its use in a tumorigenic irradiation model, which we had previously characterised studying non-steroidal anti-inflammatory drugs $^{(17)}$. The results found in this model showed that LTA
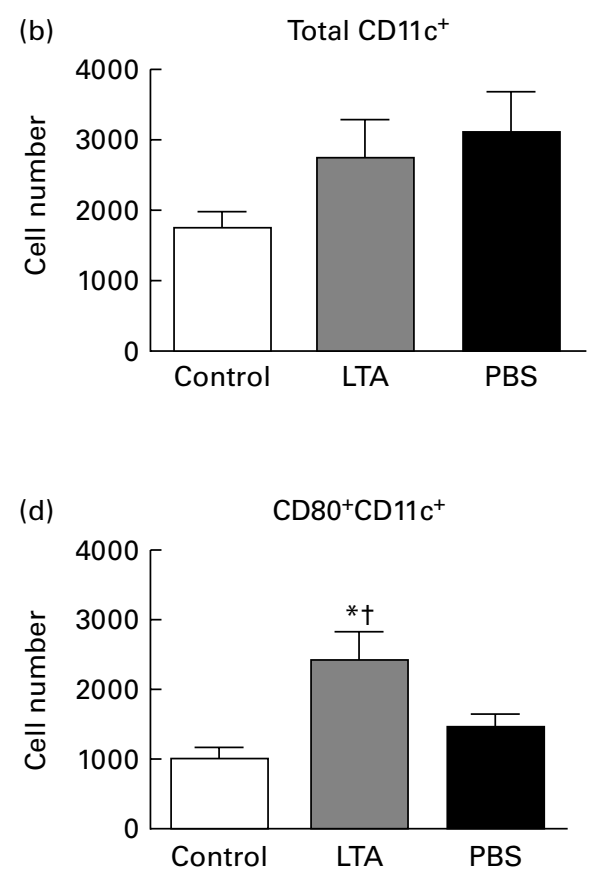

Fig. 5. Antigen-presenting cells (APC) in the mesenteric lymph nodes of chronically irradiated mice were analysed. (b) Total dendritic cells (DC), (c) total activated APC and (d) total activated DC number were obtained from (a) the dot plot of double staining with anti-CD80 and anti-CD11c. FL1, fluorescein isothiocyanate (FITC) anti-CD80 detection; FL2, phycoerythrin (PE) anti-CD11c detection. Values are means, with standard errors represented by vertical bars. ${ }^{*}$ Mean value was significantly different from that of the control mice $(P<0.05)$. † Mean value was significantly different from that of the PBS-treated mice $(P<0.05)$. 

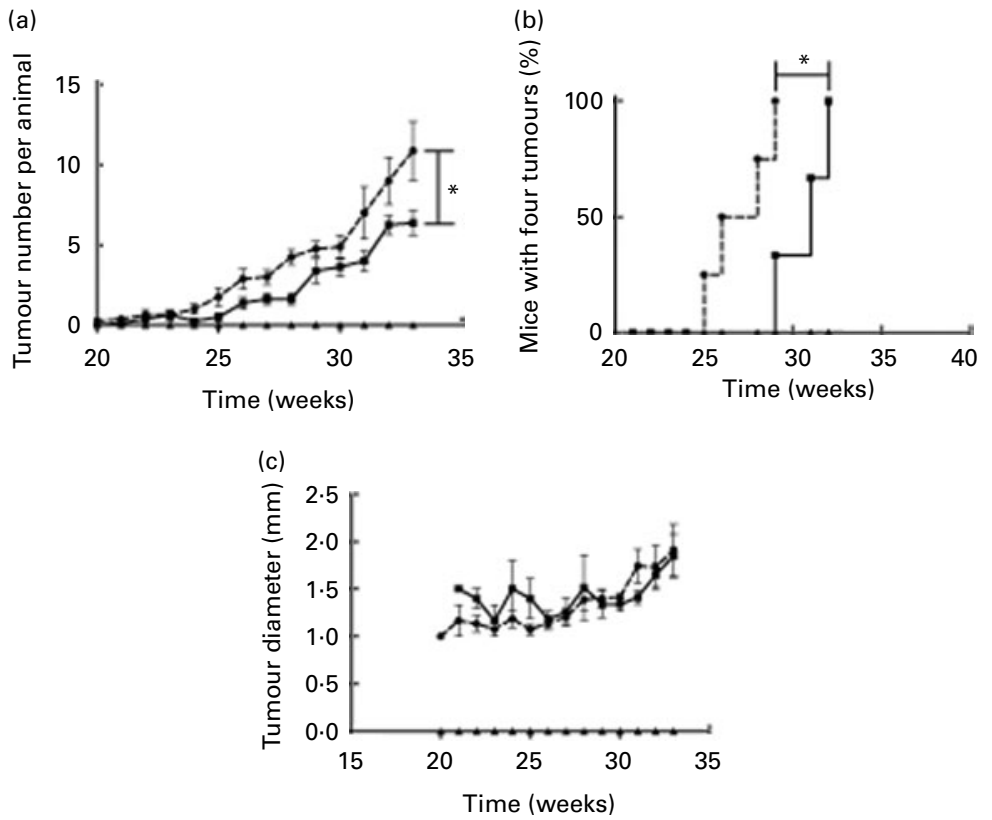

Fig. 6. (a) Tumour appearance kinetics, (b) death curve considering the appearance of the fourth tumour as a death event and (c) tumour size kinetics. Values are means, with standard errors represented by vertical bars. * Mean values were significantly different $(P<0.05)$. .

consumption delays tumour appearance. The kinetics in the appearance of tumours was significantly slower in the LTAtreated animals, since there was a 4-week difference between the appearance of the first animal with four tumours in the PBS-treated group $v$. the LTA-treated group. This period of time is clinically relevant considering life expectancy in hairless mice, which is about 2 years. The effect on tumorigenesis was exclusively associated with the delay in tumour appearance since, once installed, LTA consumption did not affect tumour size progression. The increased cellularity found in the skindraining lymph nodes of PBS-treated mice, associated with the rise in the number of total, helper and cytotoxic T-cells, is probably the consequence of the higher tumour number in this group of animals compared with the LTA-treated or the control group.

The amount of LTA given to mice in the present study was based on toxicity assays done by Cox et al. ${ }^{(13)}$, who safely administered about $2-3 \mu \mathrm{g}$ LTA/g of animal weight. In mice weighing about $30-35 \mathrm{~g}$, the amount of LTA represents approximately $100 \mu \mathrm{g}$. The animals receiving the LTA solution behave exactly in the same usual way after oral administration as did PBS-treated mice. Since LTA was obtained from a probiotic bacteria and was administered in an isotonic solution, no acute responses from mice were expected. Nevertheless, further studies considering different doses should be performed.

Finally, in the present study, we found a photoprotective effect of the consumption of an immunostimulant antigen from L. rhamnosus $G G$, a micro-organism with recognised probiotic characteristics, the consumption of which is safe and massive nowadays. This effect is reflected in tumour development delay, and it could be mediated by a transitory increase in cytotoxic and helper T-cells in the draining lymph nodes, as observed in the chronic irradiation model. Even though it is clear that the probiotic effect of a bacterium cannot be just limited to one of its antigens, it is interesting to consider the beneficial effect of the administration of subcellular fractions of these micro-organisms on the host's health. Further studies on the molecular and biochemical mechanisms underlying the effects observed are needed. Moreover, it is also very important to explore new applications and, from the industrial point of view, to develop technologies that allow improving the production and the incorporation of these molecules to food matrices.

\section{Acknowledgements}

The present study was supported by the University of Buenos Aires (UBACyT B023 grant). The authors would also like to thank the following individuals: Dr Victoria Preciado and Ms Pamela Valva for their assistance with the TUNEL assays; Ms Dolores Campos, Ms Carolina Mourelle and Ms Angélica Miranda for their technical support and advice in relation to mice care and management; Dr Daniela Ureta for her assistance in flow cytometry determinations and Dr Guillermo Nuñez for his collaboration with the manuscript revision. The authors' contributions were as follows: F. S. W. participated in the study design, carried out the animal experiments, performed the analytical determinations and data analysis, and drafted the manuscript; E. M. C. participated in the animal experiments, cellular assays and flow cytometry determinations; M. L. P. participated in the cell preparation for the flow cytometry assays and LTA administration to mice; A. F. participated in the statistical management of the data and in the discussion of the experimental design; J. L. participated in the experimental design and in the discussion of the results; D. H. G. M. participated in the experimental design, cellular assays, sample collections and microscopic analysis. All authors participated in the discussion of the manuscript and approved the final manuscript. The authors declare that they have no conflicts of interest. 


\section{References}

1. Metchnikoff E (1908) The Prolongation of Life: Optimistic Studies. New York: Putnam.

2. Lilly DM \& Stillwell RH (1965) Probiotics: growth-promoting factors produced by microorganisms. Science 147, 747-748.

3. FAO/WHO (2002) Guidelines for the Evaluation of Probiotics in Food (probiotic_guidelines.pdf, editor). London/Ontario: $\mathrm{FAO} / \mathrm{WHO}$.

4. Kleerebezem M, Hols P, Bernard E, et al. (2010) The extracellular biology of the Lactobacilli. FEMS Microbiol Rev 34, 199-230.

5. Marteau P \& Boutron-Ruault MC (2002) Nutritional advantages of probiotics and prebiotics. Br J Nutr 87, Suppl. 2, S153-S157.

6. Sharpe ME, Davison AL \& Baddiley J (1964) Teichoic acids and group antigens in Lactobacilli. J Gen Microbiol $\mathbf{3 4}$, $333-340$

7. Fischer W, Mannsfeld T \& Hagen G (1990) On the basic structure of poly(glycerophosphate) lipoteichoic acids. Biochem Cell Biol 68, 33-43.

8. Delcour J, Ferain T, Deghorain M, et al. (1999) The biosynthesis and functionality of the cell-wall of lactic acid bacteria. Antonie Van Leeuwenhoek 76, 159-184.

9. Neuhaus FC \& Baddiley J (2003) A continuum of anionic charge: structures and functions of D-alanyl-teichoic acids in gram-positive bacteria. Microbiol Mol Biol Rev 67, $686-723$

10. Buckley JM, Wang JH \& Redmond HP (2006) Cellular reprogramming by gram-positive bacterial components: a review. J Leukoc Biol 80, 731-741.

11. Ryu YH, Baik JE, Yang JS, et al. (2009) Differential immunostimulatory effects of Gram-positive bacteria due to their lipoteichoic acids. Int Immunopharmacol 9, 127-133.

12. Cerutti A (2008) The regulation of IgA class switching. Nat Rev Immunol 8, 421-434.

13. Cox F, Cook E \& Lutcher C (1986) Lack of toxicity of oral and intrapulmonary group B streptococcal lipoteichoic acid. Pediatr Res 20, 1168-1173.

14. Armstrong BK \& Kricker A (2001) The epidemiology of UV induced skin cancer. J Photochem Photobiol B 63, 8-18.

15. Svobodova A, Walterova D \& Vostalova J (2006) Ultraviolet light induced alteration to the skin. Biomed Pap Med Fac Univ Palacky Olomouc Czech Repub 150, 25-38.

16. Paz ML, González Maglio DH, Weill FS, et al. (2008) Mitochondrial dysfunction and cellular stress progression after ultraviolet B irradiation in human keratinocytes. Photodermatol Photoimmunol Photomed 24, 115-122.

17. Gonzalez Maglio DH, Paz ML, Ferrari A, et al. (2010) Alterations in skin immune response throughout chronic UVB irradiation-skin cancer development and prevention by naproxen. Photochem Photobiol 86, 146-152.

18. El-Abaseri TB, Putta S \& Hansen LA (2006) Ultraviolet irradiation induces keratinocyte proliferation and epidermal hyperplasia through the activation of the epidermal growth factor receptor. Carcinogenesis 27, 225-231.

19. Ullrich SE \& Kripke ML (1984) Mechanisms in the suppression of tumor rejection produced in mice by repeated UV irradiation. J Immunol 133, 2786-2790.

20. Byrne SN \& Halliday GM (2005) B cells activated in lymph nodes in response to ultraviolet irradiation or by interleukin-10 inhibit dendritic cell induction of immunity. J Invest Dermatol 124, 570-578.
21. Greene MI, Sy MS, Kripke M, et al. (1979) Impairment of antigen-presenting cell function by ultraviolet radiation. Proc Natl Acad Sci U S A 76, 6591-6595.

22. Gurish MF, Lynch DH \& Daynes RA (1982) Changes in antigen-presenting cell function in the spleen and lymph nodes of ultraviolet-irradiated mice. Transplantation 33, 280-284.

23. Gorman S, Tan JW, Yerkovich ST, et al. (2007) CD $4^{+} \mathrm{T}$ cells in lymph nodes of UVB-irradiated mice suppress immune responses to new antigens both in vitro and in vivo. J Invest Dermatol 127, 915-924.

24. Loser K, Apelt J, Voskort M, et al. (2007) IL-10 controls ultraviolet-induced carcinogenesis in mice. J Immunol 179, 365-371.

25. Beissert S \& Loser K (2008) Molecular and cellular mechanisms of photocarcinogenesis. Photochem Photobiol 84, 29-34.

26. Tang ML, Lahtiner SJ \& Boyle RJ (2010) Probiotics and prebiotics: clinical effects in allergic disease. Curr Opin Pediatr 22, 626-634.

27. Gueniche A, Benyacoub J, Buetler TM, et al. (2006) Supplementation with oral probiotic bacteria maintains cutaneous immune homeostasis after UV exposure. Eur J Dermatol 16, 511-517.

28. Arck P, Handjiski B, Hagen E, et al. (2010) Is there a 'gutbrain-skin axis'? Exp Dermatol 19, 401-405.

29. Morganti P (2009) The photoprotective activity of nutraceuticals. Clin Dermatol 27, 166-174.

30. Bouilly-Gauthier D, Jeannes C, Maubert Y, et al. (2010) Clinical evidence of benefits of a dietary supplement containing probiotic and carotenoids on ultraviolet-induced skin damage. Br J Dermatol 163, 536-543.

31. Roselli M, Finamore A, Britti MS, et al. (2006) Probiotic bacteria Bifidobacterium animalis MB5 and Lactobacillus rhamnosus GG protect intestinal Caco-2 cells from the inflammation-associated response induced by enterotoxigenic Escherichia coli K88. Br J Nutr 95, 1177-1184.

32. Goldin BR \& Gorbach SL (2008) Clinical indications for probiotics: an overview. Clin Infect Dis 46, Suppl. 2, S96-S100 (discussion S144-S151).

33. Weill FS, Cela EM, Ferrari A, et al. (2011) Skin exposure to chronic but not acute UV radiation affects peripheral T-cell function. $J$ Toxicol Environ Health A 74, 838-847.

34. Morath S, Geyer A \& Hartung T (2001) Structure-function relationship of cytokine induction by lipoteichoic acid from Staphylococcus aureus. J Exp Med 193, 393-397.

35. Dogi CA, Weill F \& Perdigon G (2010) Immune response of non-pathogenic gram $(+)$ and $\operatorname{gram}(-)$ bacteria in inductive sites of the intestinal mucosa study of the pathway of signaling involved. Immunobiology 215, 60-69.

36. Kim JH, Seo H, Han SH, et al. (2005) Monoacyl lipoteichoic acid from pneumococci stimulates human cells but not mouse cells. Infect Immun 73, 834-840.

37. Kruisbeek AM, Shevach E \& Thornton AM (2004) Proliferative assays for $\mathrm{T}$ cell function. Curr Protoc Immunol (Chapter 3, Unit 3.12)

38. Shreedhar V, Giese T, Sung VW, et al. (1998) A cytokine cascade including prostaglandin E2, IL-4, and IL-10 is responsible for UV-induced systemic immune suppression. J Immunol 160, 3783-3789.

39. Hooper LV \& Macpherson AJ (2010) Immune adaptations that maintain homeostasis with the intestinal microbiota. Nat Rev Immunol 10, 159-169.

40. Ohmatsu H, Kadono T, Sugaya M, et al. (2010) $\alpha 4 \beta 7$ Integrin is essential for contact hypersensitivity by regulating migration of T cells to skin. J Allergy Clin Immunol 126, 1267-1276. 